\title{
Evaluation Axisymmetric Analysis of Thermal Stress Residual Near Fiber/Epoxy Interface
}

\author{
Aboubakar Seddik Bouchikhi \\ Department of Mechanical Engineering, University of Sidi Bel Abbes, \\ BP 89, Cité Ben M’hidi- Sidi Bel Abbes 22000, Algeria
}

Received: July 10, 2008; Revised: April 16, 2009

\begin{abstract}
The finite element method is used to compute and analyze the residual stresses particularly near the fiber/ epoxy interface, and these stresses need to be taken into account. An axisymmetric model has been used for stress computation and analysis, in this work two cases are considered by using an epoxy matrix with respectively glass and carbon fibers with a different volume fiber. Numerical calculation results show that the stresses are important. The interface is affected by thermal stresses particularly in the free edge. The normal and shear stresses values have an influence on the behaviour of the composite during service.
\end{abstract}

Keywords: fiber/epoxy, thermal residual stresses, axisymmetric model, energy release, finite element method

\section{Introduction}

During the process of elaboration of composite materials both the matrices and the fibers are subjected to thermal cure temperature ranging from 120 to $150{ }^{\circ} \mathrm{C}$. In such a case the residual thermal stresses in the composite material are generated from the differential thermal expansion coefficients of components referred to as thermal residual stresses. Many research works have been carried out in this topic ${ }^{1-6}$. Other works and investigations made on bimaterial systems ${ }^{7-14}$ show the importance of residual stresses due to solid state bonding (thermo-compression). All the works on this subject recommend to take into consideration residual stresses during the material analysis. From a maintenance technique point of view, composite materials are used for reinforcement of undamaged plates and structures or to repair cracks in aeronautical metallic structures. These stresses have a great effect on the debonding between the fiber and the matrix. In this study a finite element method is used to compute and analyze the residual stresses particularly near the fiber/matrix interface where they are the most important.

\section{Geometrical Model}

For this study, the geometrical model used is an axisymmetric type plate shown in Figure 1a and b. Consider a plate whose dimensions are: Height $=254 \mathrm{~mm}$, width $=254 \mathrm{~mm}$ and composed of fibre and a matrix, where $\mathrm{R}$ and $\mathrm{w}$ are respectively their radii in the proportion $\mathrm{R}=\mathrm{k} . \mathrm{w}(0<\mathrm{k}<1), \mathrm{k}$ is the percent of volume fibre. The plate is subjected to a distributed thermal load on the two components assuming axisymmetric conditions. Since the geometry and loading are both symmetric, only one half of the structure needs to be analysed.

The material properties of fibres and matrix are:

Fibers:

i. Fiber of Glass: Young's Modulus $\mathrm{E}_{f}=4500 \mathrm{MPa}$, Poisson coefficient $v_{f}=0.3$, Expansion coefficient $\alpha_{f}=0.5 \mathrm{E}-05 /{ }^{\circ} \mathrm{C}$.

ii. Fiber Carbon HR: Young Modulus $\mathrm{E}_{f}=230000 \mathrm{MPa}$, Poisson coefficient $v_{f}=0.3$, Expansion coefficient $\alpha_{f}=0.05 \mathrm{E}-05 /{ }^{\circ} \mathrm{C}$.

iii. Epoxy matrix: Modulus $\mathrm{E}_{m}=4500 \mathrm{MPa}$, Poisson coefficient $v_{m}=0.4$, Expansion coefficient $\alpha_{m}=11 \mathrm{E}-05 /{ }^{\circ} \mathrm{C}$.
The analysis of the configuration given in Figure 1a is carried out by using the well known finite element code Franc2D developed at Kansas University ${ }^{15}$. The global structure is meshed by using standard eight noded-isoparametric elements with quadratic shape functions. Due to the importance of the results, a mesh refinement near the interference has been made for accurate results. These elements are suitable and perform well for elastic analysis. Figure 2 shows the finite element modelling. The distribution between fiber /interface/epoxy interdistance equal to (h) has been analyzed. Computation and analysis of the energy releases $G_{I}$ and $\mathrm{G}_{\mathrm{II}}$ for a crack at the interface are carried out for the cases under consideration.

\section{Results and Discussion}

\subsection{Case 1: Glass/epoxy}

The results are obtained for a thermal loading of $\Delta \mathrm{T}=-\left(120-20{ }^{\circ} \mathrm{C}\right)$ and two cases of per cent of fiber content: $\mathrm{k}=40 \%$ and $\mathrm{k}=60 \%$.

\subsubsection{Shear stresses}

For a volume of fiber of $40 \%(\mathrm{k}=0.4)$ the variation of the shear near the interface for two levels (the middle of plate and the free edge) are shown in Figure 3. Maximums are precisely reached at the interface and the ultimate is on the free edge and is equal to $145 \mathrm{MPa}$. The distribution of shear stress for the case of $\mathrm{k}=0.4$ is represented in Figure 4, on which the free edge effect appears clearly with a maximum value equals to $21.26 \mathrm{Ksi} \approx 149 \mathrm{MPa}$ (Legend of Figure 4). For a fiber volume of $60 \%(\mathrm{k}=0.6)$, the same observations are made as shown in Figures 7 and 8.

The maximum of the shear stress is about $115 \mathrm{MPa}$ observed in Figure 7, and about $19.58 \mathrm{Ksi} \approx 135 \mathrm{MPa}$ observed in Figure 8 .

\subsubsection{Normal stresses}

The evolution of normal stresses according to the width near the interface are shown in Figures 5 and 9 respectively with a volume 


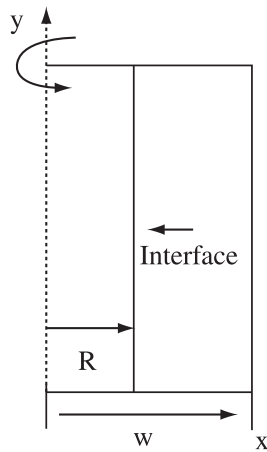

(a)

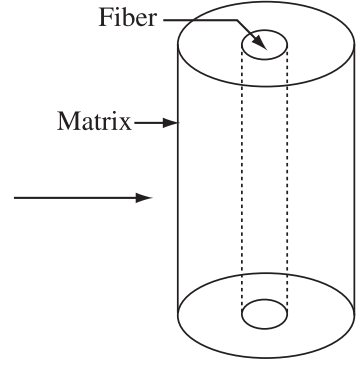

(b)
Figure 1. a) and b) Axisymmetric Model.

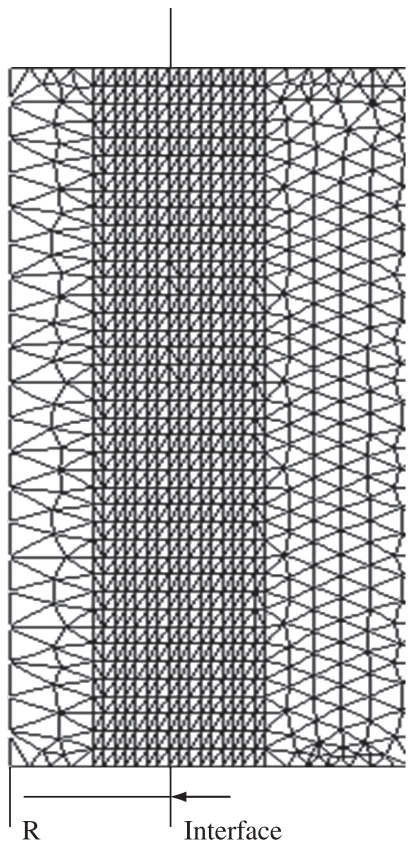

Figure 2. Typical mesh model of the mode.

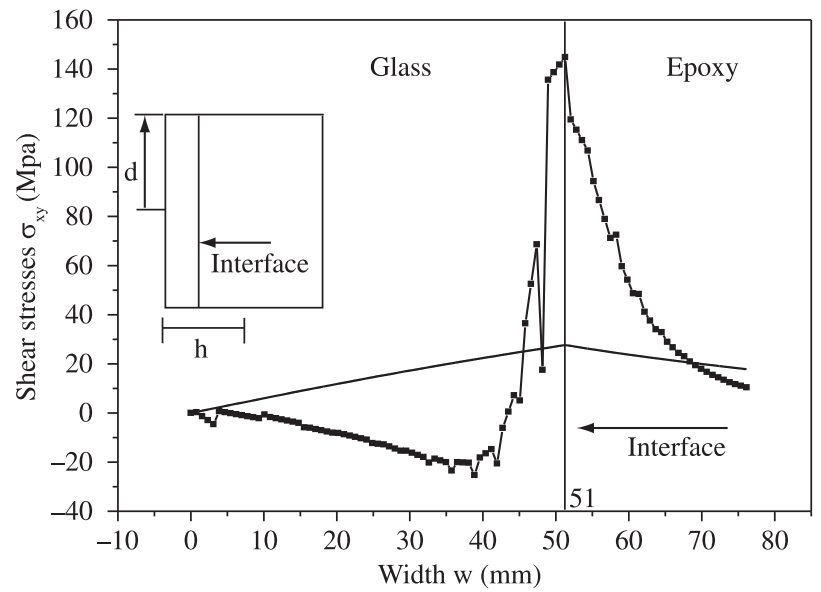

\section{$\longrightarrow \mathrm{d}=254 \mathrm{~mm}$ (at the free edge) $\mathrm{d}=0 \mathrm{~mm}$ (at the middle)}

Figure 3. Shear stresses near the interface $(\mathrm{k}=0.4)$.
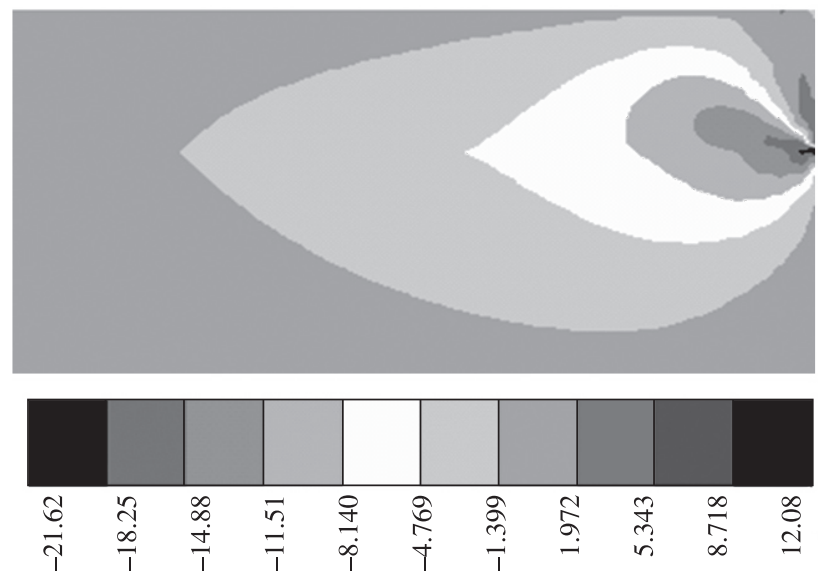

Figure 4. Repartition of shear stresses $(\mathrm{k}=0.4)$ : Legend: Ksi.

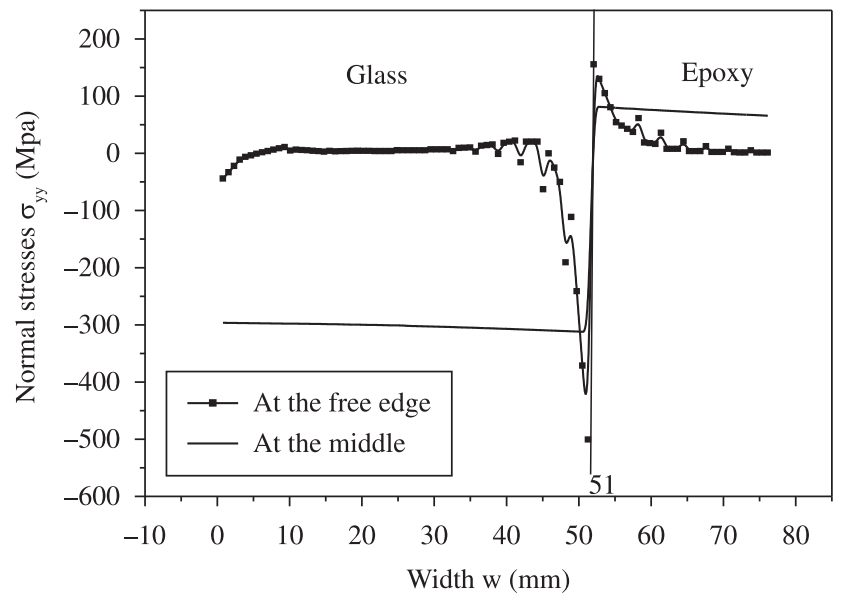

Figure 5. Normal stresses near the interface $(\mathrm{k}=0.4)$.

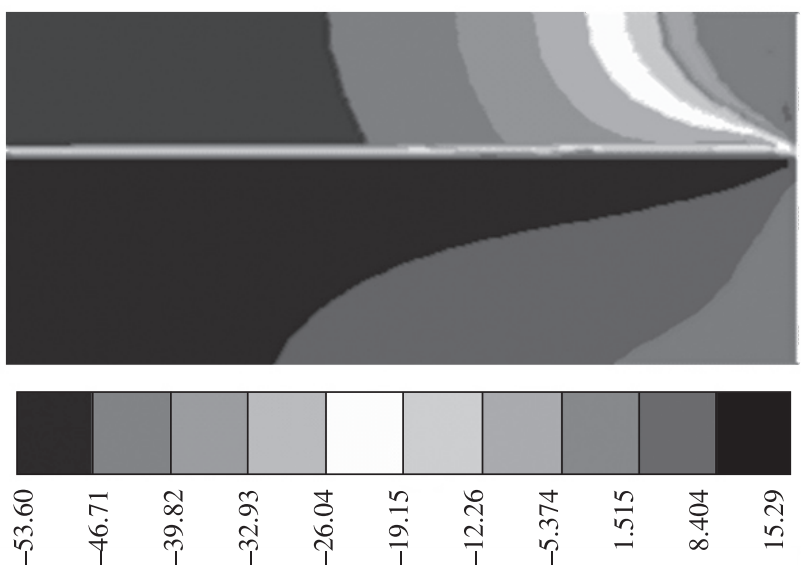

Figure 6. Repartition of normal stresses $(\mathrm{k}=0.4)$ : Legend: Ksi.

fiber content of $\mathrm{k}=0.4$ and $\mathrm{k}=0.6$. It can be noted a discontinuity of stresses at the interface resulting in a compression of the fiber and extended matrix. Figures 6 and 10 show the stress distribution on the plate, where the same observations are made as previously.

In the middle of the plate a total compression of the fiber is observed, but at the free edge the compression is less meaning that 


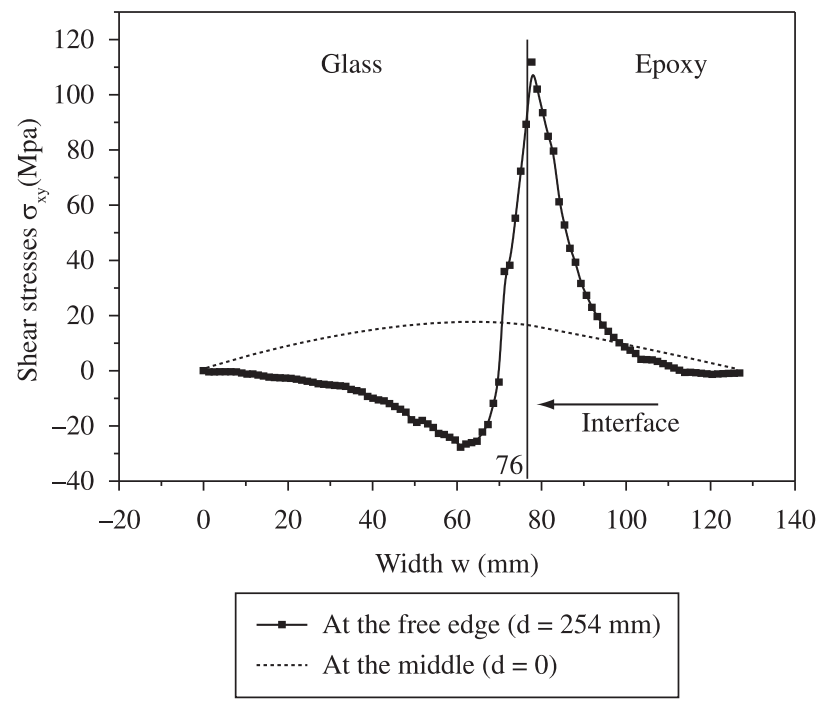

Figure 7. Shear stresses vs. width $(\mathrm{k}=0.6)$.
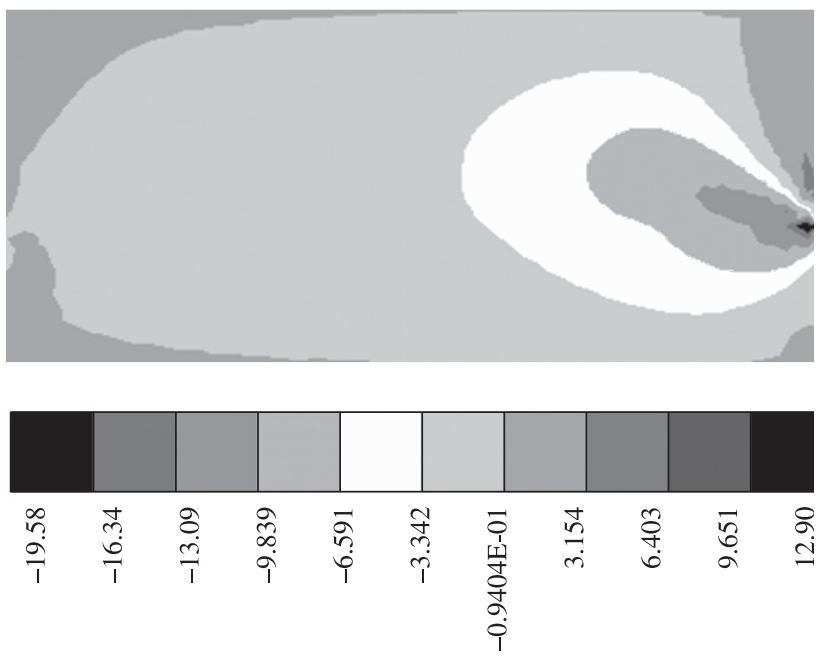

Figure 8. Repartition of shear stresses $(\mathrm{k}=0.6)$ : Legend: Ksi.

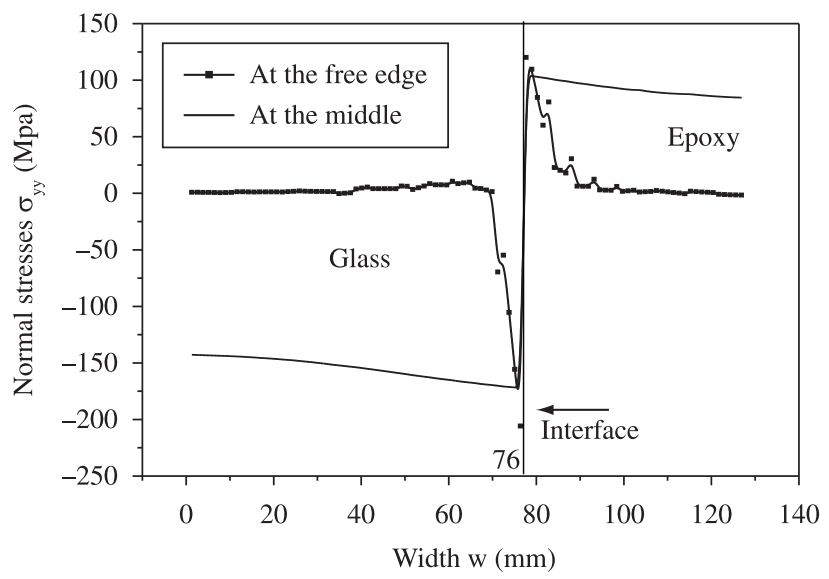

Figure 9. Normal stresses vs. width $(\mathrm{k}=0.6)$. the fiber is loaded - perhaps near the interface with the maximum of $-500 \mathrm{MPa}$ for $\mathrm{k}=0.4$ shown in Figure 5, and $-200 \mathrm{MPa}$ for $\mathrm{k}=0.6$ as shown in Figure 9.

\subsubsection{Fiber concentration}

\subsubsection{Shear stresses}

When the volume percent of fiber concentration changes from $\mathrm{k}=0.4$ to $\mathrm{k}=0.6$, the maximum shear stress varies from $150 \mathrm{MPa}$ to $115 \mathrm{MPa}$ as shown in Figures 3 and 7. Figures 6 and 10 show that the maximum stress changes from -21.62 to $-19.58 \mathrm{MPa}$.

\subsubsection{Normal stresses}

In this case, the normal stress changes from -500 to $-200 \mathrm{MPa}$ compression state of the fiber when $\mathrm{k}$ changes from 0.4 to 0.6 as represented in Figures 4 and 8. On the other hand Figures 6 and 10 show the variation of the maximum normal stress changing from -53.60 to $-27.02 \mathrm{MPa}$.

\subsubsection{Energy}

The evolution of $G_{I}$ and $G_{I I}$ energies are shown respectively in Figures 11 and 12 according to crack length $c$ at the interface. It can be observed from the plots the linearity behaviour of $\mathrm{G}$.

\subsection{Case II: Carbon/epoxy}

In this case the results obtained are for a thermal loading of $\Delta T=\left(-120^{\circ},-20{ }^{\circ} \mathrm{C}\right)$ and two different volumes of fiber content
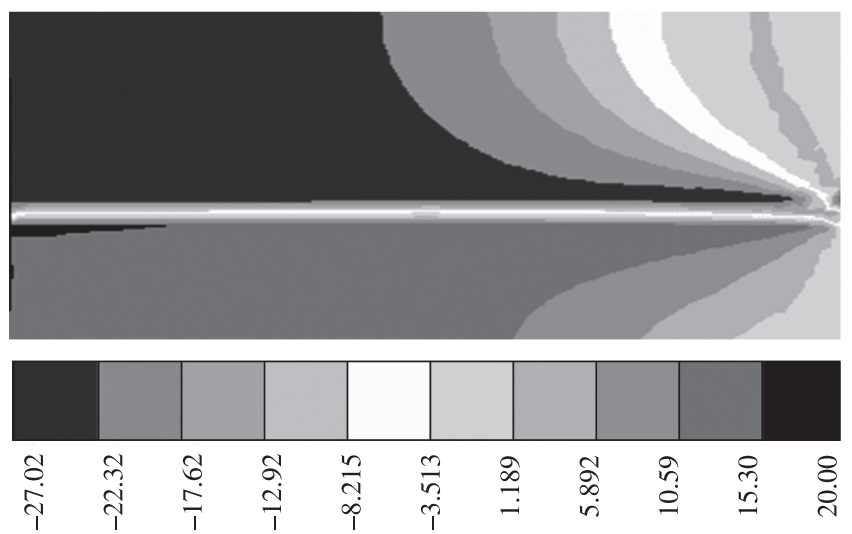

Figure 10. Repartition of normal stresses $(\mathrm{k}=0.6)$ : Legend: Ksi.

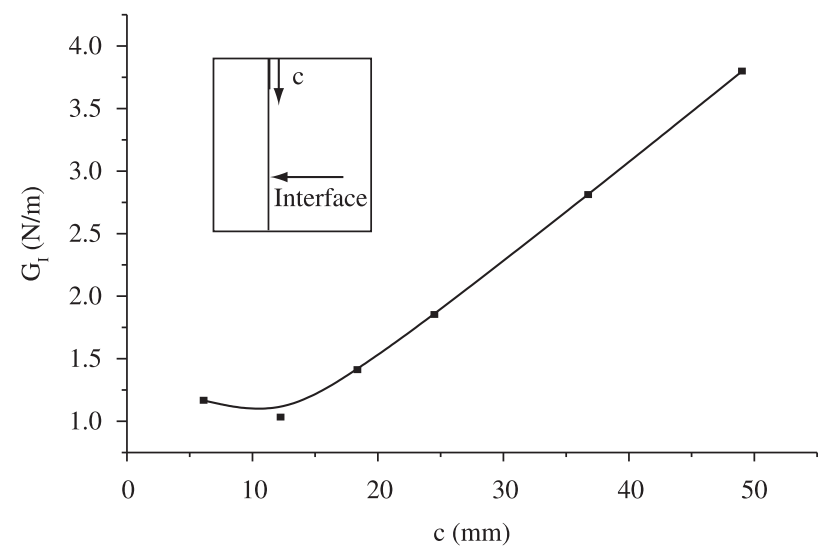

Figure 11. $G_{I}$ vs. crack length. 
respectively 40 and 60 per cent. The thermal residual stresses of carbon /epoxy at the interface have approximately the same behaviour as other fiber/epoxy matrices. Thus, only two plots are shown for comparison with glass/epoxy.

\subsubsection{Shear stresses}

The evolution of shear stresses are shown in Figures 13 and 15 respectively for $\mathrm{k}=0.4$ and 0.6 with respect to the width $w$. It can be noted that the maximums are reached at the interface for both cases $(\mathrm{k}=0.4$ and 0.6$)$. The maximum value of the shear stress is $180 \mathrm{MPa}$ for $\mathrm{k}=0.4$ and $130 \mathrm{MPa}$ for $\mathrm{k}=0.6$. The maximum stress value decreases when the volume of fiber increases. It can also be noted in the middle of the plate the decrease of the maximum shear stress as shown in Figures 13 and 15.

\subsubsection{Normal stresses}

The representations in Figures 14 and 16 show the evolution of normal stresses vs width respectively for $\mathrm{k}=0.4$ and 0.6 . It can be observed a compression of fibers while the matrix is in tension at two position levels (middle and edge) for both cases of fiber concentrations. The compressive load changes from -250 to $250 \mathrm{MPa}$ at the free edge of the interface for $k$ changing from 0.4 to 0.6 .

\subsection{Comparison between glass/epoxy and carbon/epoxy}

The stress comparison is made at the interface free edge for two loadings of fiber concentrations. It is found that for $\mathrm{k}=0.4$ the maxi-

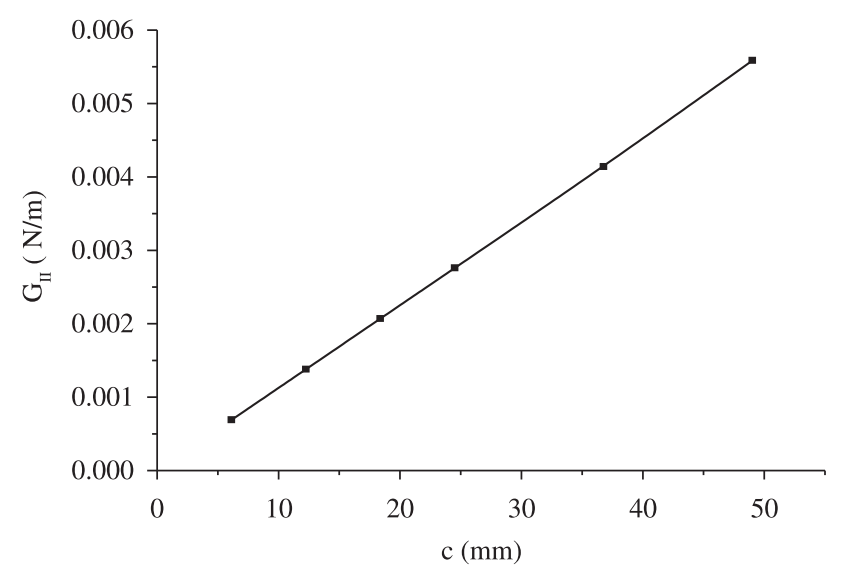

Figure 12. $\mathrm{G}_{\text {II }}$ vs. crack length.

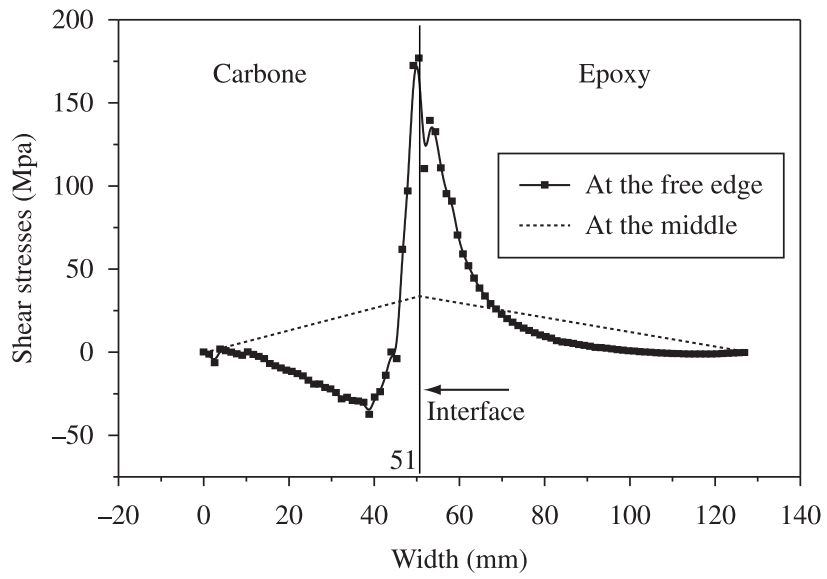

Figure 13. Shear stresses vs. width $(\mathrm{k}=0.4)$.

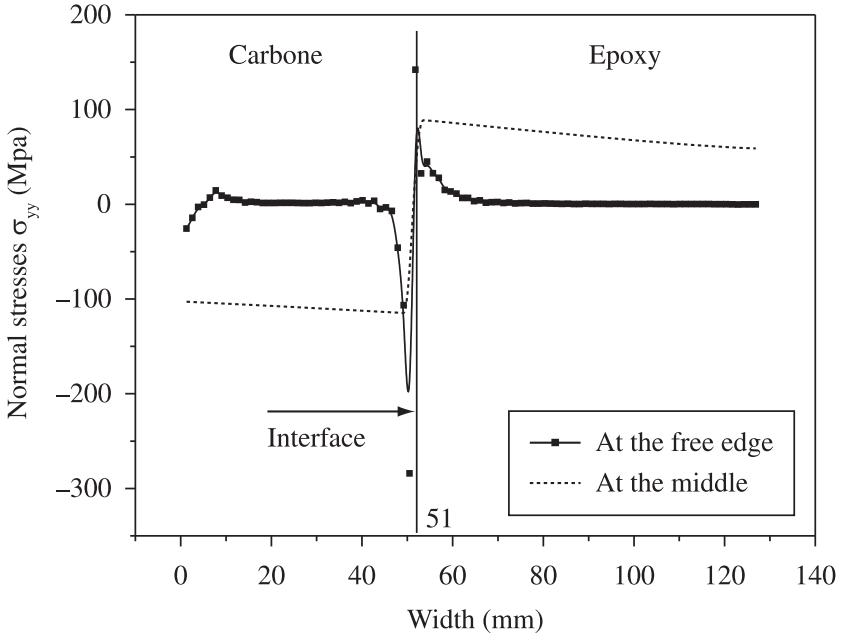

Figure 14. Normal stresses vs. width $(\mathrm{k}=0.4)$.

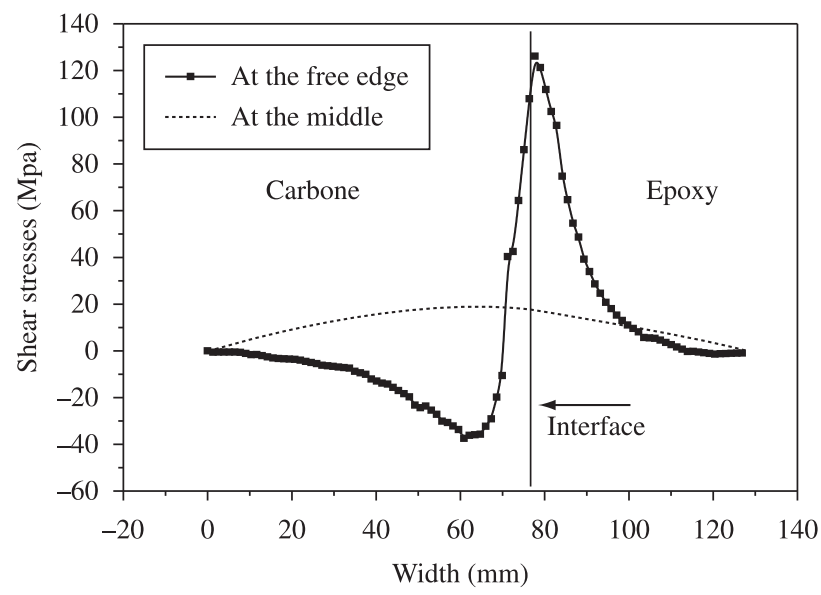

Figure 15. Shear stresses vs. width $(\mathrm{k}=0.6)$.

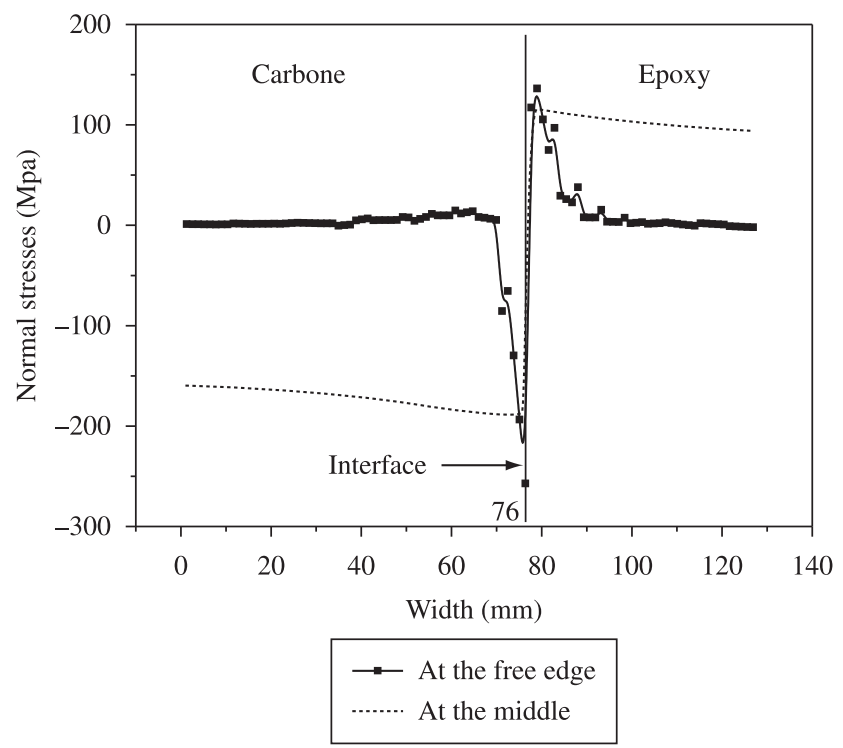

Figure 16. Normal stresses vs. width $(\mathrm{k}=0.6)$. 
mum shear stress is about $115 \mathrm{MPa}$ for glass/epoxy and $180 \mathrm{MPa}$ for carbon/epoxy. For $\mathrm{k}=0.6$ the maximum compression is $-200 \mathrm{MPa}$ for glass/epoxy and -280 MPa for carbon/epoxy. This is due to the fact that the expansion coefficient of carbon/epoxy is lower than the expansion coefficient of glass/epoxy.

\section{Conclusion}

In this study an axisymmetric model has been used for stress computation and analysis. The model gives good results in agreement with those of other authors. From the analysis the following conclusion can be made:

- The geometric discontinuity induces a discontinuity of normal stresses, which means that the fibers are compressed and the epoxy is extended;

- The value of shear is maximum on the free edge of interface;

- The fibers are compressed with a maximum of stress at the interface;

- The maximum of stresses (shear and normal) decreases when the volume per cent of fibers increases;

- The energy release rate has a linear behaviour;

- These thermal stresses can damage the interface and favour the creation of cracks;

- The main result is that we must increase the volume percentage of fiber if we must diminish the thermal residual stresses;

- We must also make the difference of expansion coefficients between fiber and matrix as small as possible; and

- Finally, we have to optimise conditions between the parameter of difference of coefficients and the volume of fibers.

\section{References}

1. Eijpe MPIM, Powell PC. A modified layer removal analysis for the determination of internal in polymer composites. Journal of Composite Material. 1997; 10(3):334-352.

2. Turnbull A, Maxwell T, Pillai S, White J. Residual stress in Polymeric mouldings: measurement good practice. [S.L.]: Springer; 1998. NPL Guide $\mathrm{N}^{\circ} 10$
3. Clyne TW, Gill SC. Residual stresses in thermal spray coatings and their effect on interfacial adhesion: a review of recent work. Journal of Thermal Spray Technology 1996; 5(4):401-418.

4. Knight R, Smith RW. Residual stress in thermally sprayed coatings. In: Proceedings of the National Thermal Spray Conference; 1993; Anaheim. [S.L.]: [s.n.]; 1993. p. 607-612.

5. Charalambides PG. Fiber debonding in residually stressed brittle matrix composites. Journal American Ceramic Societe 1990; 73(6):1674-1680.

6. He MY, Wu BX, Evans AG, Hutchinson JW. Inelastic strains due to matrix cracking in unidirectional fiber-reinforced composites. Journal of Composite Material. 1994; 18(3):213-229.

7. Bae JS, Krishnaswamy S. Subinterfacial cracks in bimaterial systems subjected to mechanical and thermal loading. Engineering Fracture Mechanics. 2001; (68):1081-1094.

8. Meyer M, Schmauder S. Thermal stress intensity factors of interface cracks in bimaterials. International Journal of Fracure. 1992; 57(5):381-388.

9. Zhang $\mathrm{S}$. Thermal stress intensities at an interface cracks between two elastic layers. International Journal of Fracture. 2000; 106(1):277-290.

10. Naim JA. Energy release rate analysis for adhesive and laminate double cantilever beam specimens emphasizing the effect of residual stresses. International Journal of Adhesion and Adhesives. 2000; 20(5):59-70.

11. Madenci E, Shkarayev S, Sergeev B. Thermo mechanical stresses for a triple junction of dissimilar materials: global-local finite element analysis. Theoretical and applied fracture mechanics. 1998; 30(2):103-117.

12. Meyer M, Schmauder S. Thermal stress intensity factors of interface cracks in biomaterials. International Journal of Fracure. 1992; 57(2):381-388.

13. Santacreu PO. Calcul des contraintes résiduelles dans les assemblages céramique/métal obtenu par brasage réactif et caractéristique mécanique des interfaces [tese]. [S.L.]: L'école Polytechnique France; 1994.

14. Herrman KP, Dong M. Thermal cracking of two phase composite structures under uniform and non uniform temperature distribution. International Journal Solids Structures. 1992; 29(4):1789-1812.

15. Swensen D, James M. FRANC/2DL: a crack propagation simulator for Plane Layered Structures. Kansas: Kansas State University; 1998. User's guide, version 1.4. 
